\title{
The Motivation and Performance in the Human Resource of a University Organization in the State of Morelos*
}

\author{
Augusto Renato Pérez Mayo" ${ }^{\#}$, Fernando Romero Torres², Nohemí Roque Nieto³ \\ ${ }^{1}$ Departmen of Studies of the Organizations and Sociology of Organizations, Faculty of Accounting, Management, and \\ Informatics, The Autonomous University of the State of Morelos, Cuernavaca, México \\ ${ }^{2}$ Faculty of Accounting, Business Administration and Informatics at the Autonomous University of \\ Morelos Stare, Cuernavaca, México \\ ${ }^{3}$ Institute of Education Sciences, Autonomous University of the State of Morelos, Cuernavaca, México \\ Email: "renatomayo@hotmail.com
}

How to cite this paper: Mayo, A.R.P., Torres, F.R. and Nieto, N.R. (2018) The Motivation and Performance in the Human Resource of a University Organization in the State of Morelos. Open Journal of Business and Management, 6, 678-687. https://doi.org/10.4236/ojbm.2018.63051

Received: May 7, 2018

Accepted: July 3, 2018

Published: July 6, 2018

Copyright () 2018 by authors and Scientific Research Publishing Inc. This work is licensed under the Creative Commons Attribution International License (CC BY 4.0).

http://creativecommons.org/licenses/by/4.0/

\begin{abstract}
This article presents the results of the level of motivation and its impact on the performance of administrative workers of a university organization in the State of Morelos. Motivation is the impulses that give intensity, direction and effort to a person to achieve a goal. These impulses are affected by needs and desires, by skills, work knowledge, disposition, traits, emotions, moods, beliefs and values in the context of work, and determine behavior and performance. The study is quantitative-descriptive, field-based, and is supported theoretically under the guidance of Maslow, McGregor, Herzberg, McClelland, Vroom and of course the theory of Motivational and Hygiene Factors of Herzberg. They applied a total of 67 surveys. We conclude that the workers have a degree of dissatisfaction with regard to working conditions: lack of tools, resources and adequate equipment to carry out their work, facilities constantly adapted to carry out the work and not well distributed physically to work efficiently, ventilation conditions, cleanliness, poor hygiene, lighting and comfort.
\end{abstract}

\section{Keywords}

Motivation, Performance, Resources Human, Organization

\section{Introduction}

Consulting, research and organizational intervention around motivation in or-

*We thank the Program for the Strengthening of Educational Quality (P/PFCE-2018/) for the support granted for the publication of this article and that has to do with the improvement of the academic productivity of the Academic Bodies of the FCAeI. 
ganizations, have been widely recognized in the field of organizational theory: Maslow, McGregor, Herzberg, McClelland, Vroom, Deci, Aldag, Brief, Reeve, Pérez Mayo, Davis, Newstrom and Herzberg specifically define the school of organizational behavior.

The development of the concept of motivation can be analyzed from the point of view of the evolution and construction of human knowledge. Its origin as a system of organizational control goes back to the philosophy and contributions of ancient Greece with Socrates, Plato, Aristoteles and later with Thomas Aquinas (Pérez Mayo, Roque Nieto, and Salgado Arteaga, 2017) [1]. At the beginning, the motivation was explained in terms of the irrational and impulsive nature and in the division between the soul and the body (mind). Later, Charles Darwin proposed the idea of the genetic transmission of instinct and William James created the theory of the instinct of human motivation, the order of ideas that during the development of psychology was called as patterns of fixed action (Reeve, 2010) [2].

For the above, we can see that the motivation has a cognitive-behavioral orientation, from this point of view "it is possible to understand it as a hypothetical cause of the behavior induced by environmental conditions or that can be inferred from behavioral, and physiological expressions" (Reeve, 2010, p. 30) [2]. Then, "the study of motivation can be understood as the search for the antecedent conditions of energized and directed behavior" (Ibídem, 2010, p. 30) [2].

\section{Development}

\subsection{Motivation and Organizations}

The development of cultural and historical formations of human societies cannot be explained without the presence of the organizations. For Hofstede, G., and Schein, E. H. (1999) [3], organizations are conducted from the activities of a certain number of people trying to get a purpose and objective common explicit, through the division of functions and work through the hierarchy of authority and responsibility. Hofstede, G., and Schein, E. H. (1999) [3] it states that in organizations a key element is not a construction or a set of policies and procedures; organizations are made up of people and the relationships between them. Within these relationships, organizational factors such as motivation are generated.

The development of the concept of motivation can be analyzed from the point of view of the evolution and construction of human knowledge. Its origin goes back to the philosophy and contributions of ancient Greece with Socrates, Plato, Aristoteles and later with Thomas Aquinas. At the beginning, the motivation was explained in terms of the irrational and impulsive nature and in the division between the soul and the body (mind). Later, Charles Darwin proposed the idea of the genetic transmission of instinct and William James created the theory of the instinct of human motivation, order of ideas that during the development of psychology was called as patterns of fixed action (Reeve, 2010, May, ARP, Nieto, 
NR, \& Arteaga, DBS 2017) [1] [2].

According to Deci, in psychoanalysis, motivational impulses are related to the instinctual stimuli that explain the psyche of people. From the physiology, it is the product of a reaction of the organic system that seeks to diminish the physiological tension that is provoked by a state of deprivation or necessity. In other studies, on the side of humanism, systematic models are proposed where diverse processes are analyzed according to the strength of the motivational impulses. Social psychology addresses the issue of incentives and various aspects of cognition that mediate behavior in real contexts, while behavioral psychology emphasizes contextual reinforcements and situational aspects that affect people's behavior. It was during the decade of the seventies, when the systemic model was developed that, in conjunction with technological development, it begins to talk about intrinsic motivation (Deci, 1985) [4].

For the above, we can see that the motivation has a cognitive-behavioral orientation, from this point of view "it is possible to understand it as a hypothetical cause of the behavior induced by environmental conditions or that can be inferred from behavioral, and physiological expressions" (Reeve, 2010, p. 30) [2]. Then, "the study of motivation can be understood as the search for the antecedent conditions of energized and directed behavior" (Reeve, 2010, p. 30) [2].

On the other hand, "you can also see motivation as the processes that account for the intensity, direction and persistence of an individual's effort to achieve a goal" (Robbins, 2004, p. 157) [5]. Intensity, effort and persistence are three very important factors that can be highlighted from this definition. Intensity is how much effort a person achieves a certain goal. The effort consists of the energy applied to the work to reach the goal. Persistence refers to the time a person sustains the effort until reaching the goal.

People have many causes that explain their behavior, in this regard Reeve (2010) [2] states the following: "behavior is never caused by a single motive, but rather by a plurality of dominant and subordinate motives, which act together in a complex way" (P. 26) [2]. Each of these motives always exists at some magnitude other than zero and varies in its intensity over time. The strongest motive will have the greatest influence on the behavior. The first finding arises: pragmatically all the behavior of human beings is motivated, needs and impulses create states of internal tension that function as inputs for the organism to analyze its environment and try to satisfy this need. This dynamic can be understood in the light of the Davis Model and Newstrom in it, motivation occurs as a consequence of a need that causes tension in the organism, so that an effort is made, mediated by an opportunity to obtain the goal, which leads to behave in a certain way. Such action will bring consequences that feed positively or negatively to the organism in terms of satisfaction of the needs, directing in consequence the behavior of the individual (Davis and Newstrom, 1993) [6].

From a different perspective, Reeve (2010) [2] has highlighted the existence of a motivational process that refers to a dynamic flow of internal states that cause 
human action. This cycle consists of four main stages, which are: anticipation; activation and direction; active behavior and feedback of the result; and result.

The cycle begins with anticipation, in which the person has some expectation of the emergence of a motive, or a state of deprivation or desire to achieve a certain goal. In the activation and direction stage, the motive is activated by an intrinsic or extrinsic stimulus. Afterwards, active behavior and performance feedback are generated. It is then, as the person generates behaviors to approach the goal object or move away from something that considers an aversive object. Through the success-failure feedback, the individual evaluates the preliminary result of his directed action and, if the desire or need translated into the emergence of a motive has not been satisfied, he can reorient his behavior to achieve the satisfaction of said goal. Finally, in the result phase, the person experiences the derivation of the satisfaction of the motive.

Even if in an organization there are systems created and continuously improved for the selection, training and placement of workers in a given task there is no certainty that they will develop their activities with the intensity of effort they are capable of in situations outside of organizational life, it is a very complex phenomenon that takes place in the action phase of the behavior, which refers to what it is possible for one or more people to do. A worker can be endowed with all kinds of tools, with the necessary capacities and surpluses to carry out an activity, but this does not give any certainty that he will execute the task. The individual is unpredictable in many cases because of this complex behavior. Normally the intensity of effort of a worker is equal to the capacity multiplied by the motivation.

Motivate is to generate a movement (although the Latin root of the word is the same), a shift from one attitude towards another or from a behavior towards another "Almost all conscious behavior is motivated or caused" (Guillén 2005, p. 61) [7].

Motivation is the process by which the human being, when executing a particular task, makes the decision to occupy certain efforts to achieve certain goals or objectives with the purpose of satisfying some type of deprivation or expectation, and depending on the satisfaction of the same, in greater or lesser proportion, will depend also the effort that dedicate in the future.

These theoretical models of motivation in organizations have departed from the diverse investigations that have constituted the baggage of the subject from the studies that were undertaken in the middle of the decade of the 1940's of the experts in the area of the behavior of psychology applied at work. For the purpose of this work, the theoretical model of Herzberg, F. (1969) [8] was resumed.

As we have seen, motivation in the organization is a powerful tool that reinforces behavior and triggers the tendency to continue, that is, motivation is an internal impulse to satisfy an unmet need and achieve a certain goal.

Motivation as a strategic axis, compared to financial resources, in human resources has the ability to create a competitive advantage for their organizations. 
In general terms, employee performance depends on a large number of factors, such as motivation, evaluations, job satisfaction, training and development, etc.

Only in the motivation of employees, since it has been shown to greatly influence the performance of the organization. As proposed by Pérez Mayo and others (2017) [3], a motivated employee has his objectives aligned with those of the organization and directs his efforts in that direction. In addition, these organizations are more successful, as their employees continually seek ways to improve their work. Getting employees to reach their maximum potential at work in stressful conditions is a difficult challenge, but this can be achieved through motivation.

We are clear that the effectiveness of the organization as the degree to which the organization meets its objectives, using certain resources or motivational packages and without exerting pressure on its members. Motivation as a strategic model can define the effectiveness of the organization. That is an intrinsic relationship.

\subsection{Explication}

This theory is based on the studies done by Frederick Herzberg in the 1960s, who interviewed 200 engineers and accountants from 200 companies in the Pittsburg, Pennsylvania area. He asked the interviewed to remember for a moment the things or events related to the work that would have made them feel exceptionally well or exceptionally bad. They were also asked to indicate the intensity with which these events affected their performance and morale.

The responses of the staff were grouped into two lists: what people said affected them most or disliked them more than their work were low wages, insufficient benefits, unfavorable working conditions, job insecurity, and poor company standards or management (He called them dissatisfaction or hygiene factors). The things or events that animated them were recognition, progress, achievements, stimulating work and being their own boss, in addition to the work itself (satisfaction factors).

Herzberg concluded that the factors of dissatisfaction are what people take as part of their work, and therefore their presence does not generate a motivational impulse (Herzberg, 1969, 2011) [8] [9].

This study ruined the belief that factors such as money, job security and working conditions were powerful motivators and that if these factors were not met at work, the motivation would be negative, and if they were met, the motivation would be positive.

The central point of Herzberg's theory is that the factors of dissatisfaction and satisfiers are important by themselves and in their own way (Ibídem, 1969) [8]. Management must first deal with the factors of dissatisfaction such as a good salary, benefits, working conditions and job security as a motivational basis to prevent employee dissatisfaction. When the dissatisfaction is eliminated, the management will obtain greater results for their motivation efforts and will be 
able to focus attention on the opportunities that the employees have to perform a job with responsibilities, acknowledgments, progress and stimuli.

Given the complexity involved in motivating gifted individuals each with their own personality and their own performance in different situations, there is a risk of failure if a motivator or group of motivators is applied without taking into account the large number of variables that affect the human behavior; As has been observed, human behavior is not a simple matter, it should be considered as a system of variables in situational interactions, some of them are, of course, the factors of motivation.

\subsection{Description of the Method}

The type of design is quantitative, cross-correlation, in both describe the relationship between two or more variables, categories or concepts in a moment determined (Hernández, Fernández and Baptista, 2006) [10].

To achieve the objectives of the research, the questionnaire "Motivational and Hygiene Factors of Herzberg" was used.

As stated above, the two-factor model is constituted by hygienic factors or sources of job dissatisfaction (interest in work, responsibility, recognition, performance) and by motivational factors or sources of job satisfaction (working conditions, employment policies, etc. the company, supervision, co-workers).

With a total population of 765 , a statistical sample of 67 workers was taken. The simple random sampling technique was used for the sample, that is, individuals will be randomly selected with the same probability of being chosen.

The Analysis Unit

In this study the unit of analysis is the administrative worker either base or eventual who works in the different areas of the North Campus of the university organization.

The decision was made to use a questionnaire from Frederick Herzberg's Two-Factor Model, because, for the conclusions of this theory, a methodology of its own was developed, and the analysis performed was not only done to the activities associated with the work, but also to the factors directly related to such attitudes, also to the effects of the disposition to the accomplishment of the task on the execution of the work.

\section{Results}

In this research work the motivation that exists in the administrative workers of a public university of the State of Morelos was studied based on the model of Frederick Herzberg. The behaviors in relation to the motivation factor that we find are:

\subsection{Variables That Were Measured and Resulted: Dissatisfaction Factors \\ - Remuneration;}


- Working conditions;

- Rules and administration;

- Supervision;

- Co-workers.

\subsection{Variables That Were Measured and Resulted Satisfaction Factors}

- Progress and growth;

- The work itself;

- Recognition;

- Responsibility.

\subsection{Modifications to the Model}

Result of the analysis of the information, in Figure 1 and Figure 2, the red line describes the average degree of agreement of the subfactors of both satisfaction and dissatisfaction that were translated into the dimensions of both variables, in addition it allows us to observe that those values with a degree of agreement below the line are those that will form the motivation model for administrative workers.

It can be seen, the university workers have a certain degree of dissatisfaction in terms of adequate working conditions, such as lack of tools, resources and adequate equipment to perform their work, facilities constantly adapted to perform the work and not well distributed physically to work efficiently, poor ventilation, cleaning, hygiene, lighting and comfort conditions.

Interpersonal relationships between co-workers are also a source of dissatisfaction for university workers, this factor is very important in its relationship with the influence of norms and values on the way people work together and treat each other, concept known as social capital, that is, the quality in the interactions between people and whether they share a common perspective. When relationships within the organization are based on honesty, trust and respect, there is a spirit of goodwill and people cooperate willingly in order to achieve mutual benefits. A high level of social capital allows interactions and exchanges without friction, which help to facilitate a fluid organizational functioning. Relations based on fierce competition and self-interest can be devastating to an organization. Social capital is related to both culture and ethics and it is the task of the Institution's leaders to cultivate it.

These factors that create dissatisfaction, as can be seen, describe the employment situation.

\section{Conclusions}

The attitude of employees towards the activities they perform on a day-to-day basis can determine the success or failure of any organization. This effect is most visible when somebody is in difficult times, where survival will be dictated by the level of staff morale. 


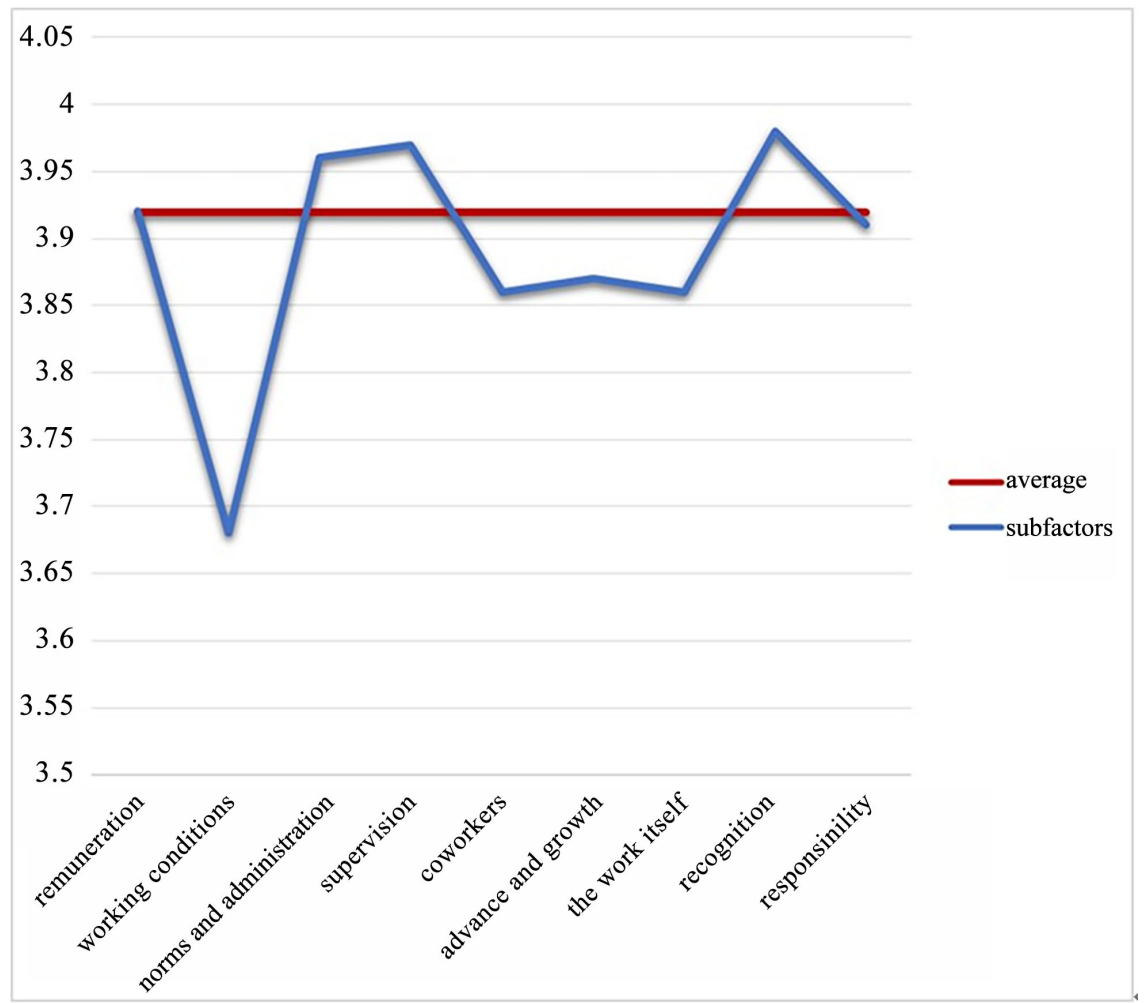

Figure 1. Degree of agreement of the subfactors. Source: Own elaboration based on the research results.

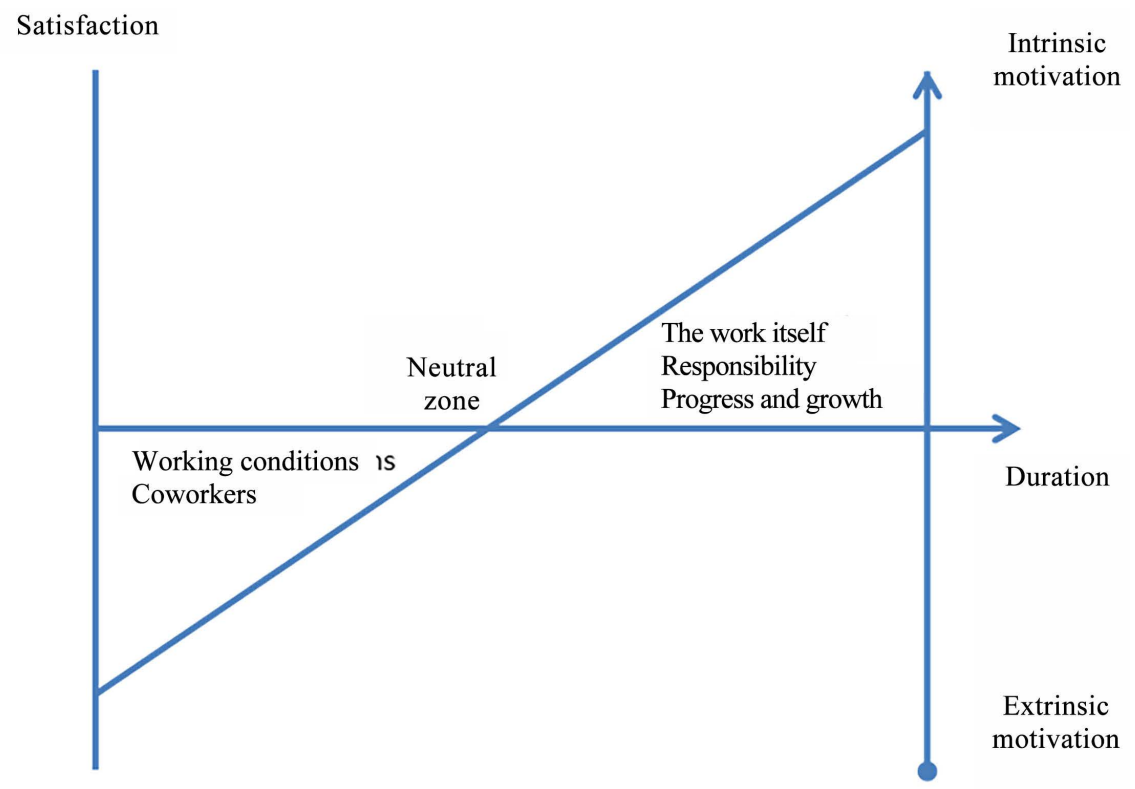

Dissatisfaction

Figure 2. Model of the motivational diagnosis existing in the administrative workers of a university organization. Source: Own elaboration based on the research results.

That is why it is very important to analyze the measurement of attitudes to understand what people expect from their work and how those attitudes affect 
performance.

When talking about satisfaction and dissatisfaction at work, it is not reflected in the same way.

The study of motivation of university workers allows through their findings, to build a specific model according to their particularities as an organization.

When workers have feelings of happiness with their activities they are often related to factors in their work in events that are successful in the execution of work and the possibility of professional development.

On the contrary, when workers have feelings of unhappiness, these are not generally related to the work itself, but are related to the conditions surrounding the execution of the work, that is, the physical and abstract spaces; hence the worker's perception of whether the context in which he performs his work is fair or if it is not, if it is disorganized and represents a hostile psychological environment or not. The factors associated with these situations are called hygienic, as an analogy to medical hygiene, that is, it is preventive of diseases, not curative. This means that when there are hostile factors in the context of work, they contribute to deficient work attitudes. When the levels of these factors fall to what workers consider the minimum acceptably, it results in job dissatisfaction.

It can be observed in this regard, that university workers have a certain degree of dissatisfaction in terms of adequate working conditions, such as lack of tools, resources and adequate equipment to perform their work, facilities constantly adapted to perform the work and not well physically distributed to work efficiently, poor ventilation, cleaning, hygiene, lighting and comfort conditions.

Interpersonal relationships between co-workers are also a source of dissatisfaction for university workers; this factor is very important in its relation to the influence of norms and values on the way in which people work together and treat each other, a concept known as social capital, that is, the quality in relationships between people and if they share a common perspective. When relationships within the organization are based on honesty, trust and respect, there is a spirit of goodwill and people willingly cooperate in order to achieve benefits for all. A superior index of these positive social relationships allows for interactions and exchanges without collisions, which help facilitate smooth functioning in the organization. Relationships based on hard competition and self-interest can be devastating for an organization. Social capital is related to both cultural values and ethics and it is the task of the institution's leaders to increase it positively.

These factors that create dissatisfaction, as can be seen, describe the work situation, that is, they are the characteristic elements of the contextual scope in which the work is developed. Improving the working conditions of university staff and cultivating good interactions among peers could eliminate dissatisfaction and could be very short-lived motivators (another example of this, as seen above, is the performance evaluation of workers administrative), however, do not create satisfaction and therefore do not really motivate, but as has been said, create the minimum acceptable conditions for workers to carry out their activi- 
ties, arrive, so to speak, to a neutral zone.

\section{Recommendations}

An organizational intervention program to improve the working conditions of university staff and cultivate good interactions among peers could eliminate dissatisfaction and could be very short-lived moratoriums to reach the desired neutral zone.

\section{References}

[1] Pérez Mayo, A.R., Roque Nieto, N. and Salgado Arteaga, D.B. (2017) Epistemology of Optimization Models for Decision Making in Organizations. International Journal of Human Resource Studies, 7, 220-242. https://doi.org/10.5296/ijhrs.v7i3.11644

[2] Reeve, J. (2010) Motivación y emoción. McGraw-Hill, Madrid.

[3] Hofstede, G. and Schein, E.H. (1999) Cultura organizacional. Culturas Y Organizaciones. El Software Mental. La Cooperación Internacional Y Su Importancia Para La Supervivencia, 8, 32-54.

[4] Deci, E. and Ryan, R.M. (1985) Intrinsic Motivation and Self-Determination in Human Behavior. Springer Science \& Business Media, Nueva York.

[5] Robbins, S.P. (2004) Comportamiento organizacional. Pearson educación, London.

[6] Davis, K., Newstrom, J.W., Sánchez, R.M.R. and Esponda, J.R.P. (1991) El comportamiento humano en el trabajo: Comportamiento organizacional. 8va ed., McGraw-Hill Mexico, México.

[7] Guillén Gestoso, C. and Guil Bozal, R. (2000) Psicologia del trabajo para relaciones laborales.

[8] Herzberg, F. (1969) Una vez más? cómo motivar a sus empleados? Harvard Business Review, 81, 67-76.

[9] Herzberg, F., Mausner, B. and Snyderman, B.B. (2011) The Motivation to Work. Vol. 1, Transaction Publishers, Piscataway, New Jersey.

[10] Hernández Sampieri, R., Fernández Collado, C., Baptista Lucio, P., et al. (2006) Metodología de la investigación. 